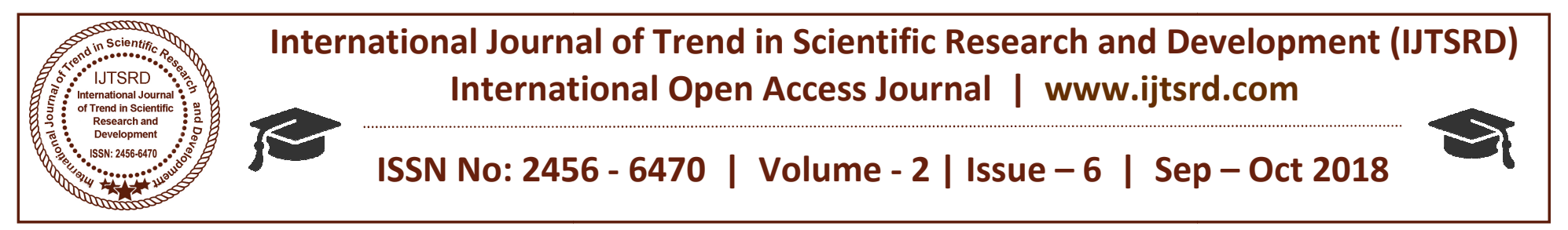

\title{
Computational Approach to Analyze Political Behavior, Culture and Policies to Understand the Revolution of a Society
}

\author{
Arijit Bag \\ Indian Institute of Science Education and Research Kolkata, \\ Mohanpur, Nadia, West Bengal, India
}

\begin{abstract}
Computational method is developed to understand the political behavior, culture and policies of a society. It is shown that from political behavior, culture and policies of a society, direction and amplitude of social revolution may be measured which helps to find out the political standing of a society at any time. The knowledge of political standing would help to predict the results of any political election. This methodology is applied to predict the assembly election result 2016 of West Bengal, India. Finally, published result is compared with computed result. It is observed that one of the computed results fits extremely well with the exact result. This method is very good for post election analysis to understand the demand of the society which should help to run better government.
\end{abstract}

Keyword: political behavior, political culture, political policy, revolution, political stand point, computational methodology

\section{INTRODUCTION}

Political behavior [Kinder and Kiewiet 1979, Norris 2004] of a society is the reaction against any governing policy of a society. It depends on personal or general loss or profit. Political behavior on the basis of loss and profit, particularly in the economic sense, is introduced by Downs [Downs 1957] and elaborated by Lip set [Lip set 1960], Kramer [Kramer 1971], Feldman [Feldman 1982] etc. This directly reflects on the electoral process [Tufte 1978 and Norris 2004] (for a review of this literature see [Monroe 1979]). To study the effect of political behavior on any electoral process we have to measure this in a quantitative way. In three different ways we can measure it - a. direct action (protest or support by count of protesting or supporting events), b. indirect action (cultural presentation by count per cultural
Events) and c. reflective action (count by utilization or participation). Thus, we may write -

Political behavior $=\left(C_{1} \mathrm{x}\right.$ direct action $+C_{2} \mathrm{x}$ indirect action $+C_{3} \mathrm{x}$ reflected action)

Where, $\mathrm{C}_{1}, \mathrm{C}_{2}$ and $\mathrm{C}_{3}$ are contribution coefficient and $\mathrm{C}_{1}+\mathrm{C}_{2}+\mathrm{C}_{3}=100$. Political behavior is a short time property of a society. It exists till the process exists or new policies announced. On the other hand political culture [Onderco and Wanger 2015, Morgan and Watson 1991] of a society is the time average value of political behavior. Political culture is the attitude of a society towards politics. Thus, to understand the political culture of a society very close observation for a long time is required. It is political culture which defines the political behavior of a society at any instance. By knowing the culture properly, one can have a guess as to the response to a particular policy, but the reverse is not true. It is very much important to know the type of dependence on political behavior on its culture to understand the political stand point of a society from its behavior. Behavior is a direct observable parameter where as culture is an indirect observable. We can define political culture as follows

Culture = Total number of response / (total time period $\mathrm{x}$ total number of policy)

Political policy of the government and political culture of the society regulate political behavior of the society. Culture is a unidirectional vector. Its action directed towards the imposing policy of the government. Whereas, government policy is a three dimensional vector. It may be a rule to control the society (direction to society), may be a rule to control the body of the government itself (direction to 
government), and may be a policy for the society (direction perpendicular to both society and government). To explain, we may consider three policies. Let, a government announces the enhancement of tax. Obviously, it is directed to the society. Let, the supremo of the government declares to audit the expanses of different government departments, it must be of the second kind. Actions taken against antisocial activities may be considered as the third kind. If political culture of a society is very much reactive we should observe huge instant response from the society against every policy at its announcement. If the culture is non-interactive, society would not react to any policy.

To know the political stand point of a society we have to know the output of mutual interaction of above mentioned three parameters. The trajectory of the political stand point in time would say whether a society is tending to revolution or not. If we plot we plot response against three different policies in three mutually perpendicular axes say, $\mathrm{X}, \mathrm{Y}$ and $\mathrm{Z}$, keeping society in $\mathrm{X}$-axis, Government in $\mathrm{Y}$-axis and independent policy in Z-axis, then the resultant vector would define the revolution of the society. If we project the values of $Z$-axis to the $X-Y$ plane, we shall get the resultant vector in the $X-Y$ plane. If the resultant vector makes an angle less than $45^{\circ}$ with $X$ axis, revolution is positive else negative. Positive revolution implies society is against the government. Less the value of angle between resultant and $\mathrm{X}$-axis, more the progress of revolution.

But, to convert the political stand point of a society into a decimal number is not obvious. Also, relating behavior with culture and policy is another challenging task. But, we can measure the amount of revolution in an indirect way. First, we setup parameters for political behavior, political culture, policy and revolution. Using these parameters we may have an expression of electoral result. From electoral result we get the relative values of these parameters. Then, by plotting the relative values we shall get the value of revolution. In this article, digitization of political parameters is done and used for computational analysis to predict the result of assembly election of West Bengal, India.

\section{Methodology:}

Measurement of political behavior (pb) - Political behavior $(p b)$ is a three component parameter. For simplicity we may consider equal contribution of these three components; direct action ( $d a$ ), indirect action (ida) and reflected action $(r a)$. Hence, we can write

$\mathrm{pb}=0.33 * \mathrm{da}+0.33 * \mathrm{ida}+0.33 * \mathrm{ra}$

Direct action (da) is the average effect of a political policy (pp) on society and may be defined as $\mathrm{da}=($ number of support - number of protest $) /($ number of support + number of protest $)$

Indirect action (ida) is the protest or support of a policy cited in the literary art (i. e. poem, story, drama, novel etc) and performing art (i. e. cinema, theater etc). Evaluation of this parameter is difficult in practice though we may define it in a very simple way as follows -

$i d a=$ density of support - density of protest

where,

density of support or density of protest $=($ number of support or protest $) /($ number of incidents $)$

Categorize and evaluate reflected action $(r a)$ is the most difficult one as it is the effect of one policy on other policy or general event. This may be explained with an example. Reflected action of a policy on economy may be verified by change of share value. Thus, we can't generalize this parameter. We have to express it depending on the policy.

Measurement of political culture (pc) - Political culture is the measure of sensitivity of a society to politics, i. e. whether it is sensitive or tolerant. It is mentioned earlier that political culture $(p c)$ is the time average of $p b$. Thus, $p c i$, pc of ith policy, would be

$$
\text { pci }=\left(\sum_{j} \Delta T_{j}\right) /\left(n_{i}\right)
$$


where, $\Delta T j$ is the time difference between time of application of $\mathrm{j}^{\text {th }}$ policy and time of a protest or support and $n i$ is the total number of protest and support (irrespective of protest or support) for $i^{\text {th }}$ policy. Thus, $p c$ is the average of $p c i$.

Measurement of political policy (pp) - Political policy ( $p p)$ is the average policy with respect to time which may be written as -

$$
p p=N /\left(T_{1}-T_{N}\right)
$$

$T_{1}$ and $T_{N}$ are the time of policy-1 and time of policy-N and $N$ is total number of policy implied within this time span.

Measure of political stand point (psp) and revolution - We may represent the numerical value of political stand point ( $p s p)$ at any time $T$ as -

$p s p_{T}=p s p_{0} *\left\{1+p c *\left(p b_{1}+p b_{2}+\ldots \ldots p b_{N}\right) /\left(T_{1}-T_{N}\right)\right\}$

It is difficult to measure psp0. But, comparing equation -7 with standard equation of a straight line we may conclude that slope of equation-7 is $\mathrm{pc}^{*}\left(p b_{1}+p b_{2}+\ldots \ldots p b_{N}\right) /\left(T_{1}-T_{N}\right)$. Hence, numerical value of revolution is defined as follows -

$$
\text { revolution }=p c^{*}\left(p b_{1}+p b_{2}+\ldots \ldots p b_{N}\right) /\left(T_{1}-T_{N}\right)
$$

In equation-8 $\left(T_{1}-T_{N}\right)$ is always negative as $T_{1}<T_{N}$. Thus, if number of protest is greater than number of support then value of revolution would be positive. That means, society is not satisfied with the governing authority and preparing for revolution. If the value of revolution is greater than 1 , there is very high chance of mutiny.

Prediction of political election result - Using the value of revolution $(R)$ of a society we can predict the result of any political election. If the value of $R$ is greater than 0.5 , then there is likely to change of present government. But, local values of $R$ may differ from global value of $R$. These effects may yield wrong result. Thus, for better accuracy, $\mathrm{R}$ should be calculated at the unit constitutional level. If $G P$ is the total vote of governing party and $O P$ is that of opposition party of previous election at the unit constitutional level then result of a particular constitution should be governed by the sign of $\boldsymbol{W}$, where $\boldsymbol{W}$ is as follows -

$\boldsymbol{W}=(G P-G P * R)-(O P+G P * R)=G P-O P-2 * R * G P$

If $\boldsymbol{W}$ is positive, ruling party will win else opposite party. In Equation (9), for $R>0.5, \mathrm{~W}$ is always negative irrespective of the value of $O P$ and $G P$. Thus, opposition will win. Now, the question is what the exact meaning of $R=0.5$ ? If we consider opposition people don't change their mind (condition-1) during this period, then $R=$ 0.5 implies $50 \%$ supporters of governing party has changed their mind against the present government. If we exclude the condition-1, then, $\mathrm{R}$ will imply an effective change. If we consider $G P-O P$ very close to 0 (condition-2), then $R=0.5$ implies $25 \%$ of total voters have changed their mind. In terms of revolution we can say revolution is $25 \%$. If $O P$ is very small, say near to 0 , then $R=0.5$ implies $50 \%$ revolution. Thus, we can conclude that $50 \%$ revolution always guarantees of inversion of a government.

For effective revolution $\boldsymbol{W}$ is negative. Applying this condition (condition-3) as on Equation 9 we get,

$G P-O P<2 * R * G P$

or,

$R>(G P-O P) / 2 G P$

if $(G P-O P)=X$ (say),

$R>X / 2 G P$ 
From Equation 10 we get the minimum value of $R$ for effective revolution which is proportional to $X$, the vote difference between parties and inversely proportional to the total vote of ruling party. For binary political system, $\mathrm{GP}+\mathrm{OP}=100$. Thus, $2 \mathrm{GP}=\mathrm{X}+100$. Putting this value in Equation 10 we get

$$
\mathrm{R}>\mathrm{X} /(\mathrm{X}+100)
$$

From Equation 11 we can estimate minimum value of $R$ for effective revolution i.e. changes of government. A plot of $R$ vs $X$ is presented in Figure-1P. For very small value of $X, R$ is nearly proportional to $X$. For example, for $X=1 \%, R \min =0.01 ; X=2 \%, R \min =0.02$ etc., which implies when opposition is very strong political tolerance is very less. In other ways we can say that, at such situation society is very unstable towards political impedance which contradicts to our common knowledge of democracy. But present day experiences all over the world we should conclude that outcome of this work is very much true; particularly in India. In India, where opposition is very strong political crime is more.
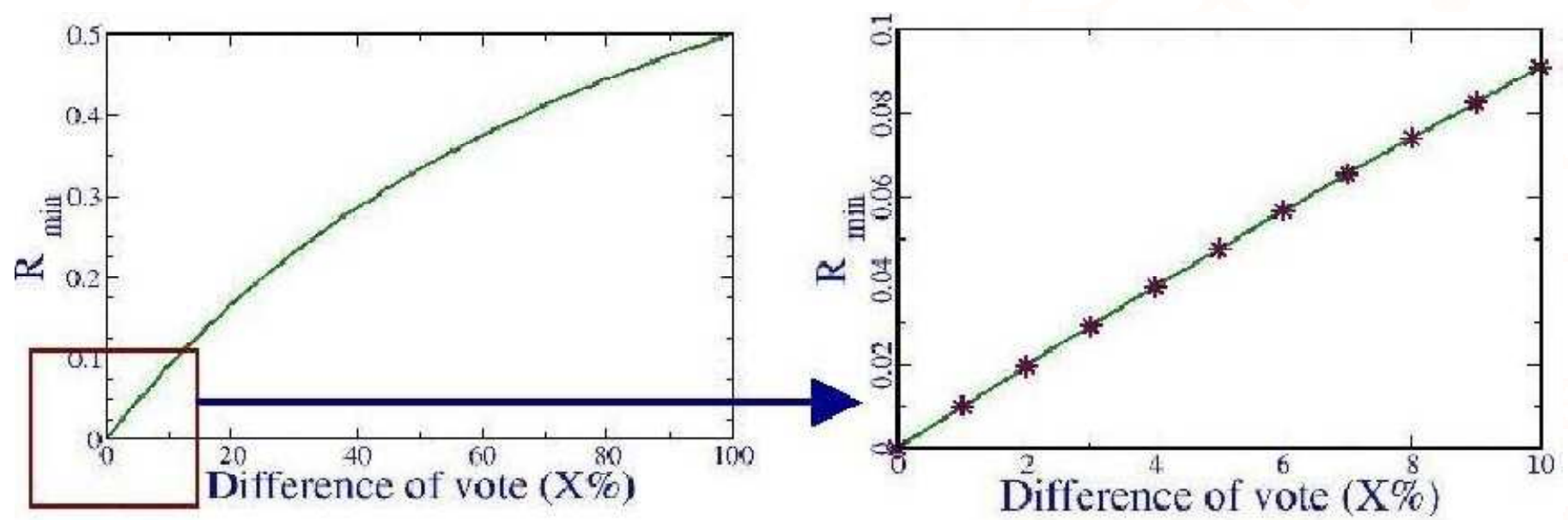

\section{Figure-1P : Variation of $\mathbf{R}_{\min }$ with respect to difference of vote \% (X)}

\section{Computational details:}

In home programming written in FORTRAN - 90 [Fox 1990] is used for data analysis and calculation for result prediction. Grace [Turner 2005] programming is used for graphs plotting. For implementation of this method to predict assembly election 2016 result of West Bengal, India, 2014 parliament election data are used as previous vote share.

\section{Implementation details:}

Present method is implemented for the prediction of assembly election 2016 result of West Bengal, India. Situation is not straight forwarding for this implementation because the contest is not confined to two parties only. There are several opposition parties. But for simplicity, only two major parties are taken as opponent. Conflict between these two parties is also presents. Also, only few major policies are considered here.
Opponents: TMC, Alliance (CPIM, CPI, National Congress, RSP, FB) and BJP

\section{Policies:}

1. Effect of Alliance

2. Effects of Narada and others

3. Effects of development

4. Change of focus

5. Partition function

Data compilation is done using 2014 Parliamentary election results. On that basis change of focus remarkably affected BJP vote which is supposed to decrease. Effect of development and scam (Narada and others) are opposite to each other. I have taken the scam as the dominating factor else it is obvious that TMC would reform W. B. Government again and there would be no need for analysis. I have to study the effects first individually and then collectively. From these results I have taken the optimized values of all parameters for final calculation. 


\section{Results and discussions:}

Figure-1: Variation of seats with respect to BJP vote loss at fixed TMC vote

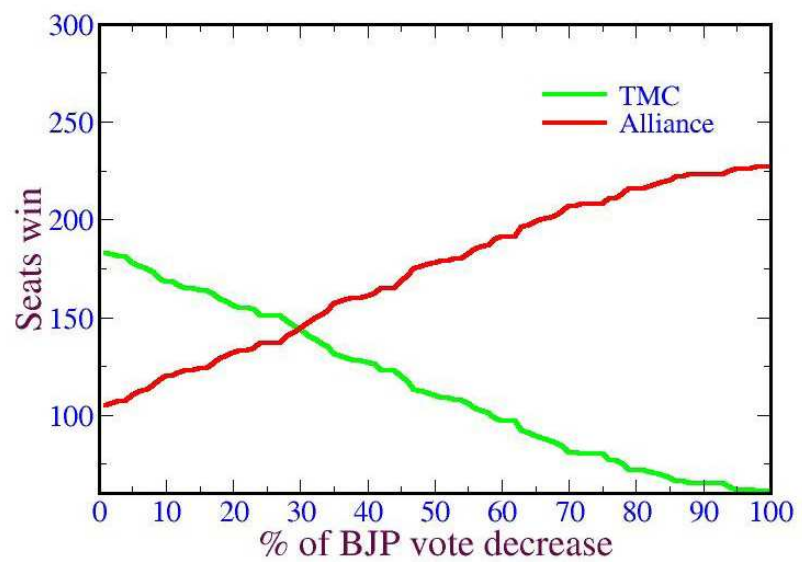

First I have study the variation of seats of TMC and Alliance with change of BJP vote from 0 to 100 percentage of its own vote. Results are presented in figure-1 and figure-2. In figure-1, it is considered that all votes from BJP go to Alliance. It is found that at $0 \%$ loss of BJP vote TMC may win 183 seats and Alliance may win 105 seats provided other parameters remains constant. On the other hand, at $100 \%$ loss Alliance may win 227 and TMC only 61 seats. It is also found that if BJP loss more than $28 \%$ vote then TMC would not get the majority. Thus this value may be termed as Majority Loss Point (MLP).

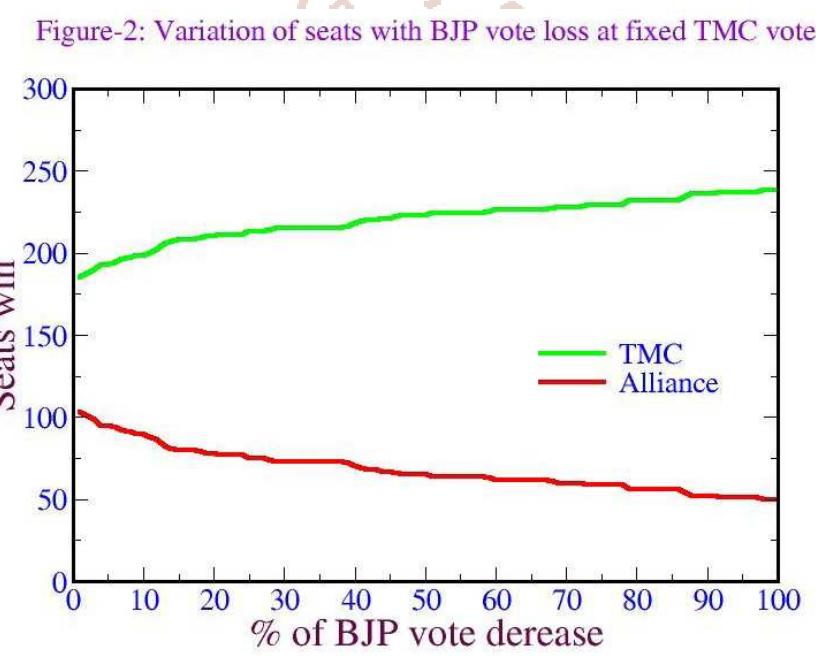

In figure-2, it is considered that all vote from BJP go to TMC. Here we found that TMC may get 185 to 238 seats with increase of BJP vote loss.

After study of two extreme situations I study the variation of seats if lost vote of BJP is partitioned between TMC and the alliance. It is obvious that equal partition would always yield one result which is $\mathrm{TMC}=185$ and Alliance $=103$. I have studied the variations for $1: 2,1: 3,1: 4$ and 1:5 distribution of lost vote of BJP between TMC and Alliance. Calculated results are presented in Table-1 From the calculated values of MLP we may conclude that TMC retains even nearly $84 \%$ lost vote of BJP is shared by Alliance until a huge (nearly $40 \%$ ) decrease of BJP vote.

Table-1: Dependence of partition function

\begin{tabular}{|c|c|c|c|}
\hline $\begin{array}{c}\text { Partition } \\
\text { function }\end{array}$ & TMC & Alliance & $\begin{array}{c}\text { MLP of } \\
\text { TMC }\end{array}$ \\
\hline $1: 2$ & $183-140$ & $105-154$ & 86 \\
\hline $1: 3$ & $183-114$ & $105-180$ & 57 \\
\hline $1: 4$ & $183-101$ & $105-193$ & 47 \\
\hline $1: 5$ & $183-90$ & $105-204$ & 43 \\
\hline
\end{tabular}

Thus, if TMC is successful to contain its vote share, most likely TMC would reach the magic figure of 148. But, due to so many unwanted incidences vote bank of TMC may decrease. I have studied the outcome of TMC vote decrease from 0 to $10 \%$. Outcome of this study is presented in figure-3. MLP of this case is 6 . Thus, if TMC loses $6.0 \%$ of its vote share compare to that of 2014 election, would not be able to form Government.

Figure-3: Variation of seats with TMC vote loss at fixed BJP vote

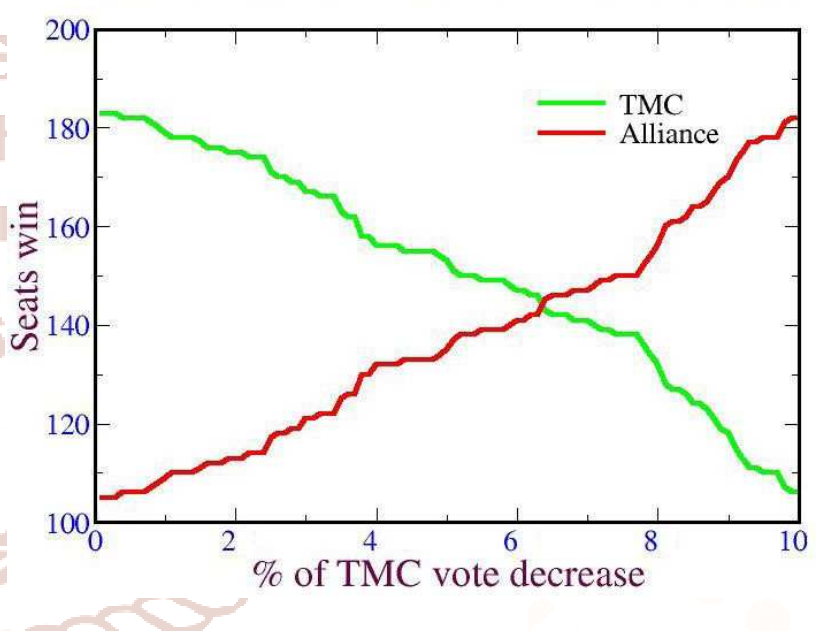

So far, it is observed that loss of BJP vote and TMC vote would trouble TMC to form their second term Government. Thus, I have taken both these parameters as positive parameters for final calculation. A double variation shows marginal shifts of MLP with respect to single variations at equal partition. But MLP for TMC vote loss reaches to $3.0 \%$ and for BJP vote loss reaches to $35 \%$ with respect to partition function variation in favor of Alliance. Bellow that limit TMC has always high chance of getting the magic figure. Thus, I did not study bellow that limit. Few field surveys show that TMC may lose 3-4 \% vote (from a news paper survey) and BJP may lose $36 \%$ of its own vote (from a private TV Chanel). Both these values are very close 
to the values predicted from my computational data analysis. These two values are used for final calculation. Before that I like to tell the result if BJP is successful to increase their vote percentage by $1 \%$ of total vote. At that situation, TMC hopeful to get 179 seats while BJP would be able to retain their lead as 2014 election as 18 seats. But Alliance would be able to increase their tally to 97 from 84 . Now let see seats of three parties at different partition function at $3 \%$ TMC vote loss and 36\% BJP vote loss.

Table-2: Final tally at different partition function

\begin{tabular}{|c|c|c|c|c|}
\hline $\begin{array}{c}\text { Serial } \\
\text { No. }\end{array}$ & $\begin{array}{c}\text { Partition } \\
\text { function }\end{array}$ & TMC & Alliance & BJP \\
\hline 1 & $1: 0$ & 213 & 78 & 3 \\
\hline 2 & $0: 1$ & 107 & 183 & 4 \\
\hline 3 & $1: 1$ & 167 & 123 & 4 \\
\hline 4 & $1: 2$ & 151 & 139 & 4 \\
\hline 5 & $1: 3$ & 144 & 146 & 4 \\
\hline 6 & $1: 4$ & 137 & 153 & 4 \\
\hline 7 & $1: 5$ & 128 & 162 & 4 \\
\hline
\end{tabular}

As election result is declared on $19^{\text {th }}$ May, 2016 we get the final result presented in Table-3. From this result we observe that final result match extremely well with case- 1 of Table- 2 . Result differs by 2 seats of TMC and 1 for Alliance which is exactly same as seats of the others. This deviation is only due to the absence of the fourth competitor in our calculation. Form published results we observe that vote share of BJP lost nearly $6.8 \%$ of their vote share of the previous election while TMC gains $6 \%$ and vote share of Alliance remains same which is the condition taken in case- 1 of Table- 2 .

Table-3: Final results

\begin{tabular}{|c|c|c|c|}
\hline TMC & Alliance & BJP & Others \\
\hline 211 & 77 & 3 & 3 \\
\hline
\end{tabular}

\section{Conclusion:}

Digitization of political behavior, culture and policy helps to find out quantitative value of political stand point of a society which helps to predict whether a society is moving towards a revolution or not. This method is also applicable to predict results of any political based election. The success of this method to predict results would depend on the accuracy of $p s p$. Methodology for implementation is described here. It is also proved that if we can guess the parameters accurately we would be able to predict an election result quite accurately. In practice, it is very difficult to quantify the parameters which not obvious and there is no direct way to measure. But, we can go in reverse way, that is, we can calculate social parameters from an electoral results which would help to understand the need of the society. Thus to run a better government proper analysis of after election review is very much needed where methodology presented in this article may be followed successfully.

\section{References:}

1. [Downs 1957] Downs, Anthony. "An economic theory of political action in a democracy." Journal of Political Economy 65.2 (1957): 135-150.

2. [Feldman 1982] Feldman, Stanley. "Economic self-interest and political behavior." American Journal of Political Science (1982): 446-466.

3. [Fox 1990] Fox, Geoffrey, et al. "Fortran D language specification" (1990).

4. Kinder and Kiewie 1979] Kinder, Donald R., and D. Roderick Kiewiet. "Economic discontent and political behavior: The role of personal grievances and collective economic judgments in congressional voting" American Journal of Political Science (1979) vol- 23, pp - 495-527.

5. [Kramer 1971] Kramer, Gerald H. "Short-term fluctuations in US voting behavior, 1896-1964." American political science review 65.1 (1971): 131-143.

6. [Lipset 1960] Lipset, Seymour M. "Political man: The social basis of modern politics." (1960).

7. [Monroe 1979] Monroe, Kristen R. "Econometric analyses of electoral behavior: A critical review."

Political behavior 1.2 (1979): 137-173.

8. [Morgan and Watson 1991] David R. Morgan, Sheilah S. Watson. "Political culture, political system characteristics, and public policies among the American states" Publius the Journal of Federalism (1991) vol - 21(2), pp - 36-37.

9. [Onderco and Wanger 2015] Michal Onderco, Wolfgang Wanger. "The ideational foundations of coercion: political culture and policies towards North Korea" European Political Science Review (2015) vol-1, pp- 1-24.

10. [Norris 2004] Pippa Norris. Electoral engineering: Voting rules and political behavior. Cambridge University Press, 2004.

11. [Tufte 1978] Tufte, E. (1978). Political control of the economy. Princeton: Princeton University Press.

12. [Turner 2005] P. J. Turner. "XMGRACE, Version 5.1. 19" Center for Coastal and Land-Margin Research, Oregon Graduate Institute of Science and Technology, Beaverton, OR (2005). 